\title{
An Analysis of Guizhou's International Image in CNN Reports (2011-2021)
}

\author{
Xiangjun Su \\ School of International Education, Zunyi Medical University, Zunyi, China \\ Email: 532207021@qq.com
}

How to cite this paper: Su, X. J. (2021). An Analysis of Guizhou's International Image in CNN Reports (2011-2021). Advances in Journalism and Communication, 9, 39-46. https://doi.org/10.4236/ajc.2021.92003

Received: March 29, 2021

Accepted: April 24, 2021

Published: April 27, 2021

Copyright $\odot 2021$ by author(s) and Scientific Research Publishing Inc. This work is licensed under the Creative Commons Attribution International License (CC BY 4.0).

http://creativecommons.org/licenses/by/4.0/

\begin{abstract}
Guizhou's economic and social development has entered the fast lane since 2012, and the leapfrog development of Guizhou and its enormous changes capture the attention of the whole world, making the international image of Guizhou become a concern for academia. Based on the statistics and analyses of the image of Guizhou created by $\mathrm{CNN}$ reports in the past decade, it is proposed that the international image of Guizhou should be presented more than just that of an international tourist destination, instead, it should be a multi-faceted and completely new image, which showcases dramatic changes and extraordinary achievements in the economic and social development in Guizhou. Besides, some constructive suggestions are given to enhance the international dissemination of Guizhou's international image.
\end{abstract}

\section{Keywords}

Guizhou's International Image, CNN Report, Development and Change, International Dissemination

\section{Introduction}

With the reform and development of Guizhou advancing by leaps and bounds, the image of Guizhou has been refreshed time and again. A number of image labels reflecting Guizhou's new outlook, such as "Colorful Guizhou", "Intoxicating and Beautiful Guizhou", "Mountain Park Province", "Bridge Museum", and "Ecological Civilization Pilot Zone", have gradually become showcases for the outside world to discover and re-understand Guizhou. In recent years, the historic changes in Guizhou have attracted the attention of the media at home and abroad, providing an opportunity to have the "voice" of Guizhou heard and build a new image of Guizhou. However, what does Guizhou look like in the eyes of the world? What is the impact of the international dissemination of 
Guizhou? These questions remain puzzling. Therefore, this paper attempts to probe into the international image of Guizhou by analyzing the relevant news reports by $\mathrm{CNN}$, an international mainstream news media, and provide some helpful suggestions for enhancing Guizhou's international dissemination.

\section{Development and Change of Guizhou and Status Quo of Its International Dissemination}

In history, Guizhou is often viewed as an impoverished and underdeveloped area. But today, Guizhou takes on a brand-new look after it has realized the leapfrog development in economy and society, and its stereotyped image of "being poor and backward" has turned into the new image of "having rich people and beautiful ecology". The amazing reversal of Guizhou's image is mainly reflected in the following aspects:

First, it has achieved rapid development in the economy and torn off the centuries-old label of absolute poverty. In the past decade, Guizhou's economic growth rate has ranked among the top of the country. By the end of 2020, the provincial GDP had reached 1.78 trillion yuan, and the green economy had accounted for $42 \%$ of the total regional GDP, and the economic aggregate had risen by 5 ranks and the per capita level had risen by 4 ranks in the national ranking list respectively ( $\mathrm{Li}, 2021)$. It is commendable that Guizhou, as one of the most poverty-stricken areas in China, has achieved a double victory in epidemic control and poverty alleviation in the year of the pandemic breakout. 66 poverty-stricken counties in Guizhou have shaken off poverty, achieving the development goal of building a moderately prosperous society in all respects on schedule.

Second, the infrastructures in Guizhou, particularly transportation and communications, have greatly improved. In 2015, Guizhou became the first province in western China to connect every county with expressways. In 2017, every village in Guizhou had access to asphalt roads and passenger transport ( $\mathrm{Lv}$ \& Cheng, 2019). In 2020, 5G network covered 88 counties (districts and cities) in the province. At present, it is accelerating the realization of the development goal of "making high-speed rail accessible to all cities" for the central cities in its 9 regions or prefectures. Up to now, there have been 18 expressways and 14 railway routes across the province, and 11 civil aviation airports have achieved full coverage of the whole province. Guizhou's backward situation of "Transport depends on walking on foot and information communication relies on shouting" is gone forever.

Third, the Guizhou spirit of overcoming challenges and difficulties has been cultivated and the social atmosphere of catching up and forging ahead has come into being. Under the strong leadership of the Communist Party of China, people of all ethnic groups in Guizhou seized every opportunity to develop and forged the great Guizhou spirit of "Fear no difficulty, struggle hard, overcome challenges and never retreat" in the great practice of pushing forward economic 
and social development.

In the meantime, a large number of campaigns for international dissemination have been successfully launched by Guizhou Provincial Party Committee and Provincial Government, which greatly helps to further promote economic and social development in Guizhou. On one hand, the tourism publicity was greatly strengthened. As Guizhou boasts pristine ecological environment and diverse ethnic cultures, the development of tourism and cultural industry has become the first priority. In 2005, "Colorful Guizhou" image was first created to spearhead the economic and social development of Guizhou, and later in 2016, it was spread around the world through CNN, the New York Times, France National Television 2 and other international media. Since 2006, Guizhou Tourism and Culture Industry Development Conference has been held in a different place in the province each year. Furthermore, the tourism and culture promotion conference under the theme of "Mountain Park Province, Colorful Guizhou Style" has also been widely held overseas. On the other hand, cooperation with domestic and international mainstream media was enhanced, and various international communication platforms were properly exploited. In 2016, the International Communication Development Plan of Guizhou Province (2016-2020) was released, and international communication and cooperation with China Daily, CTV Golden Bridge International, CNN, FOX and other major media were carried out actively. To further improve the global influence of Guizhou, the multilingual international publicity platform "Live in Guizhou" was set up in 2019.

\section{Analysis of CNN's Coverage of Guizhou in the Past Decade}

\subsection{Brief Introduction to CNN}

CNN (Cable News Network) is an American international mainstream media, providing 24-hour news service to the cable television network and satellite television users through satellite. It was founded in June 1980 and owned by Warner Media's Turner Broadcasting Company. Its headquarters is located in Atlanta, state of Georgia, the United States. Its news is broadcast in more than 200 countries and regions around the world, covering 2 billion people, and the average daily audience rating during the prime time in the United States reached 77 million in 2014, so CNN has a wide international influence (Li, 2016). This paper selects CNN as the research object and analyzes its relevant news reports.

\subsection{Data Acquisition and Analysis}

To explore the image of Guizhou in the eyes of the world, the author searched for the keyword "Guizhou province" on CNN website, and found 109 relevant news reports or information, including written news (stories) 80 pieces, video news (videos) 3 pieces, news pictures (photos) 26 pieces, dated from October 4 , 2011 to January 16, 2021, spanning about 10 years. In terms of the relevance of content, there were 42 news reports with Guizhou as the theme, accounting for 
$38.5 \%$. Among them, there were 7 news reports with "Guizhou" or "the name of a place in Guizhou" (such as "Getu River", a scenic area in Ziyun county of Guizhou province) in the news title, accounting for $6.4 \%$, for example, "9 reasons to visit Guizhou, China's next big travel destination", "Karsts of China's Getu River region attract rock climbers, other travelers". In contrast, there were 67 news reports that only mentioned Guizhou or indirectly concerned it, such as "Huawei Founder Ren Zhengfei: The US cannot defeat us", accounting for $61.5 \%$. In this paper, only those 42 news reports are used as the samples for statistical analysis. The theoretical framework involved in this study is the well-known " $5 \mathrm{~W}$ " Communication Model proposed by Harold Lasswell, an American expert in communication and media research, who examines an act of communication by five elements, namely, who says what in which channel (or media) to whom with what effect.

According to the content, CNN's coverage of Guizhou can be divided into six aspects: Tourism, society, economy, culture, science and technology, and archaeology. Combined with the reports of these aspects, a brief analysis is made as follows:

1) Tourism: Statistics indicate that there are 17 pieces of travel reports, accounting for $40 \%$ of the total, which is the most prominent part of CNN reports on Guizhou. Tourism development is one of the most important strategies for Guizhou to promote its economic and social development, accordingly tourism publicity is also an essential part of international dissemination and image construction of Guizhou. In recent years, $\mathrm{CNN}$ has made great efforts to publicize the ecological beauty of Guizhou hidden in the remote mountains with a large number of exquisite pictures and impressive advertising slogans, showing the image and charm of this beautiful province and attracting more and more attention from the world to Guizhou's development and changes. Relevant statistics show that, with the number of tourists coming to Guizhou growing like the "blowout", the number of foreign tourists received by Guizhou is also on the rise. But it's worth noting that $\mathrm{CNN}$ has made it clear that some of its travel reports are often commercial sponsorships. Therefore, the successful display of Guizhou's tourism image on CNN platform is, to a large extent, an effective try in international business cooperation between Guizhou's international dissemination and foreign mainstream media.

2) The social aspects: There are 15 pieces of $\mathrm{CNN}$ news report on the social aspects of Guizhou in total, accounting for 34\%, slightly less than the travel reports. These reports are concerned with social safety and stability, poverty relief, migrant workers, homeless children and the change of people's livelihood. Of the news reported, more than half are involved with social safety and stability, such as "A bus driver in China deliberately crashed and killed 21 people after his house was demolished (in Anshun)", "State media: China mine accident kills 16 (in Jinsha)", "Arrests after 15 killed in Chinese 'gambling' blast (in Kaili)", and "Dog goes on rampage, injuring 23 in street attack (in Guiyang)" and so on. 
CNN's extra attention to Guizhou's social problems fully reflects the consistent position and attitude of western media in reporting China: More negative comments than objective reports. This news reporting tradition was dubbed as "the crowlike reporting", namely reporting bad news, which essentially reveals the West's inherent ideological bias on China (Zhang, 2008), and runs counter to the universal principle of seeking truth from facts in reporting news, thus presenting a challenge to objectively introducing to the world the development and change of Guizhou.

3) Economy: Liquor industry is an important driving force for the economic development of Guizhou, which often makes the headline at home and abroad, especially the development of Kweichow Moutai, one of the three world-famous distilled liquors. Although $\mathrm{CNN}$ has only 3 pieces of news reports on Kweichow Moutai, accounting for 7\%, Kweichow Moutai, known as China's national liquor, has always attracted its attention over the past decade. With the market cap of China's Kweichow Moutai Group surpassing that of the UK's Diegeo in 2017 to become the world's largest liquor industry, the world has updated its knowledge of Guizhou once again (Toh, 2021). The economic boom of Kweichow Moutai liquor industry tells the world the story of Guizhou where quality liquors produced are credited to the green mountains and clear water.

4) Science and technology: The development trends of high-tech are one of concerns for the news media. In recent years, Guizhou has rapidly developed into the "Silicon Valley" of China's big data, attracting hi-tech giants such as Apple, Qualcomm and Huawei to settle in Guizhou one after another. In the meantime, China's major science and technology project "Sky Eye" (namely, the Five-hundred-meter Aperture Spherical Radio Telescope) has settled in Guizhou. These high-tech developments have attracted extensive attention from the media. Statistics show that CNN has reported "Sky Eye" and big data 3 times. Although all these reports are more or less biased, there is no doubt that "Sky Eye" and big data have become the new postcards for the world to know about Guizhou.

5) Culture: $\mathrm{CNN}$ has 2 pieces of reports concerning the development and protection of ethnic minority cultural tourism, accounting for only $5 \%$. Both of these two reports focus on the protection and inheritance of ethnic minority cultural traditions under the background of Guizhou's tourism development, and $\mathrm{CNN}$ continues to make negative reports, and does not objectively and truly report the diversity of ethnic cultures in Guizhou. As a matter of fact, the colorful ethnic minority culture is just an important underlying color that constitutes the colorful image of Guizhou, and it has been well protected and reasonably exploited in the process of inheritance and development. Among the 1652 designated "villages with Chinese ethnic characteristics", Guizhou accounts for 312, ranking the first in number in China.

6) Archaeology: Reporting archaeological discoveries is usually of great news value. Although CNN has only 2 pieces of reports on paleontological archaeo- 
logical findings in Guizhou, accounting for $5 \%$, it has provided historical evidence for the pristine state of Guizhou's ecological environment. The paleontological remains, discovered in Guizhou and reported by CNN, prove that there are abundant and well-preserved paleontological fossils in Guizhou, and that Guizhou is not only a little-known "kingdom of paleontology", but also a well-deserved "ecological park province".

Based on the above analysis, it can be seen that in the eyes of CNN, Guizhou is an international tourism destination with ecological beauty, a place where good mountains and waters produce good liquors, China's "Silicon Valley" of big data, and the hometown of "Sky Eye". In fact, however, Guizhou is not only an ecological Guizhou, a landscape Guizhou, a science and technology Guizhou, but also a cultural Guizhou and an open Guizhou. What's more, it is a colorful Guizhou that is undergoing tremendous changes anytime and anywhere. On the whole, the international image of Guizhou under the lens of CNN is an extension of the image of colorful Guizhou, which in essence reflects the predicament that the information transmitted abroad often becomes weakened or distorted. Therefore, there is still much room for making efforts to further enhance Guizhou's international dissemination ability and to spread the multi-faceted image of Guizhou's historic changes.

\section{Suggestions for Improving Guizhou's International Image}

In order to enhance the world's perception and understanding of Guizhou's development and changes, strengthen the construction of Guizhou's international communication capacity, and continuously improve Guizhou's image in the eyes of the world, greater efforts should be made in the following dimensions:

1) Enrich the contents of international dissemination and produce more high-quality products for international communication. The construction of tourism image is only an important breakthrough point for the international dissemination of Guizhou's image, actually the content of Guizhou's image is even richer and more wonderful. Over the years, the historic change of Guizhou is multi-faceted, international dissemination of Guizhou should not just focus on publicizing the ecological tourism resources in Guizhou, merely showing to the world the image of Guizhou with beautiful mountains and waters, but also need to tell the historic changes that happened on this promising land, presenting the new image of Guizhou to the world as well. At the same time, more international communication products popular with foreign audiences should be actively created, such as "Live in Guizhou".

2) Strengthen the cooperation with domestic and international media to enhance Guizhou's international communication capacity. Based on the experience in Guizhou's international dissemination, the cooperation with international mainstream media should continue, including CGTN (China Global Television Network), China Daily and CNN. In addition, the construction of institutions and platforms for international communication should also be strengthened, 
such as running the English government websites well, setting up an agency specifically responsible for international dissemination and cultivating local international talents, to realize a transition from dependence to self-reliance in terms of international dissemination.

3) Focus the target of international dissemination on foreign nationals in China. From a global perspective, China's international communication capacity has been significantly improved with the increase of national strength, but the current pattern of the discourse power of international communication has not changed, it is still dominated by the West. Therefore, for a certain period of time, foreigners in China should still be the main object of our international dissemination. Although the number of this group is only more than one million, they can play the role of a bridge and their demonstration effect is irreplaceable. It is advisable to hold onto the local advantages, select different measures proper for the overseas audience, make full use of various modern media technologies and communication channels, and take the initiative to "go out" to the world.

4) Pay attention to solving the problems of interlingual and cross-cultural communication in international dissemination. International dissemination is essentially a kind of behavior concerning intercultural communication, which is always challenged by language and culture differences. Therefore, to enhance Guizhou's international image and spread Guizhou's story well, more attention should be paid to solving the following cross-lingual and cultural problems: First, the lack of foreign audience awareness. News narrative expression does not conform to the thinking habits of foreign audiences: Too many word-for-word translations, grandiose words, self-talks, and unconvincing examples. Second, paying little attention to the information needs of foreign audiences. News storytelling is bland, and not good at seeing big things from small ones and recognizing the whole through observation of the part. Third, the lack of background information or context explanation. International dissemination is by no means one-way communication, and the gap in cognition and experience between the two parties needs to be filled up in time. In short, only by following the rules of international communication and using the language and style that foreign audiences love and accept to spread the "voice" of Guizhou, can we truly show the image of Guizhou.

\section{Conclusions}

The findings of this case study are of both practical significance and theoretical implication to enhancing the international communication capacity of Guizhou province. Specifically, the constructive suggestions proposed above can be a frame of reference for the authorities or institutions in charge of international dissemination, such as the Publicity Department of Guizhou Provincial Party Committee, in continuously strengthening international cooperation and improving international dissemination. 
To sum up, the striking reversal of Guizhou's image is a witness to the earth-shaking historic changes in Chinese society and refreshes the world's understanding of China and Guizhou. To tell about Guizhou's story of the huge changes, establish a good international image of Guizhou and interpret the successful secret code of the "governance of China", will not only promote Guizhou to embrace the world and continue to develop by leaps and bounds but also help the world to know about colorful Guizhou and understand wonderful China much better.

\section{Conflicts of Interest}

The author declares no conflicts of interest regarding the publication of this paper.

\section{References}

Li, B. J. (2021). Government Work Report of Guizhou Province in 2021. http://www.guizhou.gov.cn/xwdt/zy/ldhd/202102/t20210224_66836412.html

Li, Y. (2016). The Development Status and Characteristics of American Cable TV News Channels-A Case Study of CNN, Fox News and MSNBC. Journal of Extranet Media, 1, 82-85.

Lv, T. L., \& Cheng, H. Y. (2019). Great Changes in Transportation and Communication Start a New Chapter in Guizhou. http://cpc.people.com.cn/big5/n1/2019/0322/c415067-30990289.html

Toh, M. (2021). It's 53\% Alcohol and Tastes Like Fire, Here's How This Liquor Brand Took over China. https://edition.CNN.combusiness/kweichow-moutai-chinese-liquor-intl-hnk/index.ht $\underline{\mathrm{ml}}$

Zhang, T. P. (2008). The Roots and Causes of American Media's Negative Reports on China from the CNN Events. Journal of Theoretical Sciences, 8, 214-215. 